Supporting Information for:

\title{
Tuning radical relay residues by proton management rescues protein electron hopping
}

\author{
Estella F. Yee ${ }^{\dagger}$, Boris Dzikovski ${ }^{\dagger} \S$, Brian R. Crane ${ }^{\dagger, *}$ \\ ${ }^{\dagger}$ Department of Chemistry and Chemical Biology, Cornell University, Ithaca, New York 14853, \\ United States

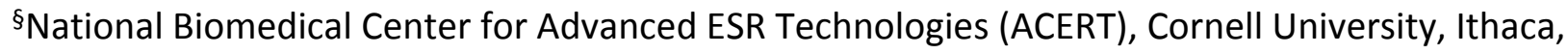 \\ New York 14850, United States
}

The PDF file includes:

Materials and Methods

Supplemental Figure 1 - Progress curves for Cpd I formation.

Supplemental Figure 2 - Crystal structure of WT CcP:CcY48K compared to that of WT CcP:WT Cc.

Supplemental Table 1 - Single and multiple turnover rate constants from reactions run in $100 \mathrm{mM}$ KPi buffer.

Supplemental Table 2 - X-ray diffraction data collection and structure refinement statistics.

Supplemental Table 3 - Estimated thermodynamic parameters affecting PCET of Tyr191'.

References 


\section{Materials and Methods}

Protein Purification

\section{Cytochrome c}

The gene for wild-type yeast iso-1-Cc from Saccharomyces cerevisiae was expressed in E. coli BL21 (DE3) cells from a PBTR1 vector ${ }^{1-3}$ that also contains the yeast heme lyase gene. Cells were grown in LB-Miller media for $20 \mathrm{~h}$ at $37^{\circ} \mathrm{C}$ with $125 \mu \mathrm{g} / \mathrm{mL}$ ampicillin and $50-100 \mu \mathrm{g} / \mathrm{mL}$ $\Delta$-aminolevulenic acid to improve heme incorporation. Harvested cells were resuspended in 50 $\mathrm{mM}$ sodium phosphate ( $\mathrm{NaPi}$ ), $\mathrm{pH} 8$ and lysed by sonication. Lysate was centrifuged at 20,000 RPM for $1 \mathrm{~h}$ at $4{ }^{\circ} \mathrm{C}$ and the supernatant was directly loaded onto an equilibrated HiPrep CMFF $16 / 10$ column (GE Healthcare). After washing with one column volume (40 mL) of $50 \mathrm{mM} \mathrm{NaPi}$, a linear gradient of $50 \mathrm{mM} \mathrm{NaPi}, 500 \mathrm{mM}$ sodium chloride $(\mathrm{NaCl}), \mathrm{pH}$ 8, was applied over 100 $\mathrm{mL}$ to elute the bound protein. Protein fractions were pooled and further purified by sizeexclusion chromatography (HiLoad Superdex 75 26/60; GE Healthcare). Colored fractions were combined, concentrated, aliquotted, and stored at $-80^{\circ} \mathrm{C}$. Concentrations were measured at $\mathrm{Abs}_{550 \mathrm{~nm}}-\mathrm{Abs}_{540 \mathrm{~nm}}, \varepsilon=19.2 \mathrm{mM}^{-1} \mathrm{~cm}^{-1}$.

\section{Cytochrome c peroxidase}

Cytochrome c Peroxidase (CcP) constructs from Saccharomyces cerevisiae were cloned into the pPSUMO pET28a-based vector to provide an N-terminal His-tag followed by a SUMO protein ${ }^{1}$. The vector was transformed into BL21(DE3) cells, which were then grown at $37^{\circ} \mathrm{C}$ in LB-Miller media with kanamycin $(50 \mu \mathrm{g} / \mathrm{mL})$. Cells were induced with $100 \mu \mathrm{M}$ isopropyl $\beta-D-1-$ thiogalactopyranoside (IPTG; $25 \mu \mathrm{g} / \mathrm{mL}$ ) once O.D.600 reached $0.8-1.2$ and overexpressed at room temperature for $\sim 18 \mathrm{~h}$. Cells were harvested and resuspended in lysis buffer $(50 \mathrm{mM}$ HEPES, pH 7.0, $150 \mathrm{mM} \mathrm{NaCl}$, and $5 \mathrm{mM}$ imidazole). Cells were then lysed by sonication and centrifuged at 20,000 RPM for $1 \mathrm{~h}$ at $4{ }^{\circ} \mathrm{C}$. CCP was purified by Ni-NTA resin (Qiagen) and concentrated. SUMO-His 6 tag was cleaved with ULP-1 protease and dialyzed into $100 \mathrm{mM}$ potassium phosphate (KPi), $\mathrm{pH} \mathrm{6,} \mathrm{overnight} \mathrm{at} 4{ }^{\circ} \mathrm{C}$. Eluent was flowed through a Ni-NTA column 
to remove the tags. To improve heme incorporation, the eluent was incubated with one molar equivalent of hemin dissolved in $500 \mu \mathrm{L} 0.1 \mathrm{M}$ sodium hydroxide $(\mathrm{NaOH})$ overnight at $4{ }^{\circ} \mathrm{C}$. The reaction was quenched with an equal amount of $0.1 \mathrm{M}$ acetic acid. Unreacted hemin and precipitated protein were removed by centrifugation at 13,000 RPM for $10 \mathrm{~min}$. The soluble portion was purified by size-exclusion chromatography (HiLoad Superdex 75 26/60) in 100 mM $\mathrm{KPi}, \mathrm{pH}$ 6. Protein fractions were combined and loaded directly onto an equilibrated HiPrep Q XL 16/10 column (GE Healthcare). A linear gradient of 500 mM KPi, pH 6, was applied over 160 $\mathrm{mL}$ to elute the protein and separate the apo-CcP from the Fe-CcP. All fractions with high heme incorporation $\left(\mathrm{Abs}_{408 \mathrm{~nm}} / \mathrm{Abs}_{280 \mathrm{~nm}}>1\right.$ ) were pooled, concentrated, aliquoted, and stored at -80 ${ }^{\circ} \mathrm{C}$. All preparations of the enzyme conformed to the purity criteria previously described 4 . Concentrations were determined at $408 \mathrm{~nm}, \varepsilon=96 \mathrm{mM}^{-1} \mathrm{~cm}^{-1}$.

\section{Site-directed Mutagenesis}

Single residue substitutions in CCP were produced by the overlap extension PCR method on the CcP construct within the ppSUMO vector. For fluorotyrosine derivatives, site 191 was replaced with a TAG amber stop codon and the final termination codon with either a TAA or TGA stop codon.

\section{Tyrosine phenol lyase}

Tyrosine phenol lyase (TPL) in pET23b (generous gift from the Tonge lab, Stony Brook University) was overexpressed in BL21(DE3)pLysS cells (Novagen) in LB-Miller media with chloramphenicol $(12 \mu \mathrm{g} / \mathrm{mL})$ and ampicillin $(50 \mu \mathrm{g} / \mathrm{mL})$ at room temperature for $18 \mathrm{~h}$. Cells were harvested, resuspended in lysis buffer (50 mM NaPi, pH 7, $150 \mathrm{mM} \mathrm{NaCl}, 5 \mathrm{mM}$ DTT), and lysed by sonication. Cell detritus was removed by centrifugation at 20,000 RPM, $1 \mathrm{~h}, 4^{\circ} \mathrm{C}$, and the resulting lysate was purified by Ni-NTA resin. The eluted protein was then further purified by size-exclusion chromatography (HiLoad Superdex 75 26/60) in 50 mM NaPi, pH 7, 150 mM $\mathrm{NaCl}$ buffer. Protein fractions were pooled and glycerol added to a final percentage of $10 \%$ to aid in stability. Samples were stored at $-80^{\circ} \mathrm{C}$ and used within one week of preparation to avoid loss of activity. Final yield was $\sim 200 \mathrm{mg}$ per $8 \mathrm{~L}$ culture. 


\section{Fluorotyrosine preparation and purification}

Fluorotyrosine amino acids were prepared as described ${ }^{5,6}$. Pyridoxal 5' phosphate and 2,6difluorophenol were purchased from Oakwood Chemicals; 2,3,6-trifluorophenol was acquired from Alfa Aesar. (Note that the numbering changes when converting the fluorophenol into fluorotyrosine.) A 1-L solution of $30 \mathrm{mM}$ ammonium acetate, $\mathrm{pH}$ 8, $60 \mathrm{mM}$ sodium pyruvate, 40 $\mu \mathrm{M}$ pyridoxal 5' phosphate, and $50 \mathrm{mM} \beta$-mercaptoethanol was prepared and filtered through a $0.22 \mu \mathrm{m}$ filter into a bottle. To this solution, $10 \mathrm{mM}$ fluorophenol was added while adjusting the final pH to 8 . Approximately 150 units ( $~ 80 \mathrm{mg}$ ) of purified TPL were added to the mixture drop-wise while stirring, after which, the reaction was covered in foil and continually stirred at room temperature. Every two days, 30 units ( 16 mg) of TPL were added to the reaction mixture for a total of $\sim 1$ week. The mixture was quenched by acidification to $\mathrm{pH} \sim 2.5$, and precipitated protein was removed by filtration or centrifugation. The solution was extracted twice with $500 \mathrm{~mL}$ of ethyl acetate to remove unreacted phenols. The aqueous layer was run through a column (inner diameter $\sim 4$ in) of activated Dowex 50W-X8 (50 - 100 mesh; Beantown Chemical Corporation) equilibrated in Nanopure water. The column was washed with $1 \mathrm{~L}$ of filtered Nanopure water to remove impurities, and the fluorotyrosine amino acids were eluted with $10 \%$ ammonium hydroxide in $\sim 7 \mathrm{~mL}$ fractions. Fractions were spotted on a silica thin-layer chromatography plate and visualized by ninhydrin stain $(0.19 \%(\mathrm{w} / \mathrm{v})$ ninhydrin, $95 \%$ ethanol, $0.5 \%$ acetic acid, $4.5 \%$ water). Fractions containing the amino acid were combined, concentrated by roto-evaporation, and lyophilized to dryness. Fluorotyrosine products were confirmed by ${ }^{1} \mathrm{H} N M R$ and ${ }^{19} \mathrm{~F} N M R$ in $\mathrm{D}_{2} \mathrm{O}^{6}$. Yield: $\sim 50 \%$.

\section{Fluorotyrosine incorporation into site 191 of CcP}

BL21(DE3) cells were co-transformed with ppSUMO containing the gene for CcP (with site 191 replaced by TAG in ppSUMO) and with a pEVOL system expressing the E3 aminoacyl-tRNA synthetase (generous gift from the Stubbe group, MIT) ${ }^{7}$. Cells were grown in LB-Miller media with kanamycin $(25 \mu \mathrm{g} / \mathrm{mL})$ and chloramphenicol $(12 \mu \mathrm{g} / \mathrm{mL})$ at $37^{\circ} \mathrm{C}$ until they reached an O.D.600 of $\sim 0.4$, after which $1 \mathrm{mM}$ of the fluorotyrosine dissolved in $0.1 \mathrm{M} \mathrm{NaOH}$ was added to the culture and incubated for 10 minutes. Subsequently, E3 expression was induced with $0.05 \%$ 
(w/v) arabinose. After $1 \mathrm{~h}, \mathrm{CcP}$ production was induced with $100 \mu \mathrm{M}$ IPTG, and cells were grown at $37^{\circ} \mathrm{C}$ for $18 \mathrm{~h}$. Cells were harvested and purified similarly as other CcP variants.

Experimental Procedures

\section{Single and multiple turnover measurements}

Single turnover measurements were conducted with $1800 \mu \mathrm{L}$ of $1 \mu \mathrm{M} \mathrm{CcP}$ and $2 \mu \mathrm{M}$ reduced Cc in $100 \mathrm{mM} \mathrm{KPi}, \mathrm{pH} 6$ buffer at $20^{\circ} \mathrm{C}$. Reactions were initiated by rapidly adding $3-4 \mu \mathrm{L}$ of $\mathrm{H}_{2} \mathrm{O}_{2}$ stock to a final concentration of $2 \mu \mathrm{M}$ while stirring at 700 RPM (Hewlett-Packard 89090A Peltier). Moderately high ionic strength ${ }^{1,8}$ and constant stirring ${ }^{9}$ allows for substantial preformed complex, prevents second-site binding, and increases Cc off-rates. The rate of $\mathrm{Cc}\left(\mathrm{Fe}^{2+}\right)$ oxidation was monitored at the heme $Q$ bands $\mathrm{Abs}_{550 \mathrm{~nm}}-\mathrm{Abs}_{540 \mathrm{~nm}}$ and the CcP oxyferryl species at $\mathrm{Abs}_{434 \mathrm{~nm}}\left(\mathrm{a} \mathrm{Cc}\left(\mathrm{Fe}^{2+} / \mathrm{Fe}^{3+}\right)\right.$ isosbestic point ${ }^{10}$ using a Hewlett-Packard Agilent 8453 spectrophotometer under Kinetics mode with a cycle time of $0.5 \mathrm{~s}$. Rate constants were obtained by fitting the Cc oxidation traces to monoexponential curves $\left(y=a \cdot e^{-b \cdot x}+c\right.$ (MatLab; Mathworks)) after removal of the first five seconds during which concentrations fluctuated and signals were unstable. Multiple turnover rate constants were similarly obtained except with $1 \mu \mathrm{M} \mathrm{CcP}, 30 \mu \mathrm{M} \mathrm{Cc}$, and $10 \mu \mathrm{M} \mathrm{H}_{2} \mathrm{O}_{2}$. An excess of $\mathrm{Cc}\left(\mathrm{Fe}^{2+}\right)$ was used to minimize effects from depletion of the pool of reduced protein, as oxidized Cc also binds to CcP.

\section{Solvent isotope effect on electron transfer rates}

$1 \mu \mathrm{M} \mathrm{CcP}$ and $1 \mu \mathrm{M}$ Cc were combined in order to maintain the stability of CcP. The complex was diluted 500-fold into $100 \mathrm{mM} \mathrm{KPi}$, pH 6 deuterium-based buffer overnight at $4{ }^{\circ} \mathrm{C}$. Cc was fully oxidized by the following morning, so an additional $2 \mu \mathrm{M}$ reduced $\mathrm{Cc}$ was added to the solution and brought up to a final volume of $1800 \mu \mathrm{L}$ before initiating the reaction with $2 \mu \mathrm{M}$ $\mathrm{H}_{2} \mathrm{O}_{2}$ at $20^{\circ} \mathrm{C}$ with constant stirring (700 RPM). Parallel studies were conducted in protic buffer for direct comparison. Data were acquired and processed similar to single turnover measurements. Statistically significant differences were determined by a two-tailed Student's $t$ test assuming equal variances. 


\section{Crystallization of CcP:Cc complexes}

$\mathrm{CCP}$ and $\mathrm{Cc}$ were combined in a 1:1 stoichiometric ratio and oxidized with potassium ferricyanide overnight. The CcP:Cc sample was exchanged into filtered Nanopure water and the final concentration was adjusted to $1 \mathrm{mM}$. Crystals of W191Y:L232E in complex with Cc formed in $2 \mu \mathrm{L}$ hanging drops within a week (drops were mixed 1:1 with well solution: $100 \mathrm{mM}$ sodium acetate, pH 5.4 - 6, 175 mM NaCl, 5 mM n-octyl- $\beta$-D-glucoside, 18\% - 20\% polyethylene glycol 3350). Crystals of W191Y:L232H in complex with Cc required 10 mM L-proline (Additive Screen HR2-428; Hampton) as a crystallization additive. The complex of WT CCP and Y48K Cc was crystallized in similar solutions from pH $4.6-5.0$ and $14 \%-20 \%$ polyethylene glycol 3350 without L-proline. Crystals were soaked briefly in $20 \%$ ethylene glycol as a cryoprotectant, flash frozen, and diffraction data were collected either at Cornell High Energy Synchrotron Source (CHESS) A1 beam line on an ADSC Quantum 210 CCD camera or at the NE-CAT Advanced Photon Source 24ID-C beam line on a PILATUS 6MF pixel array detector. All data were indexed, integrated, and scaled by HKL-2000. The structures were determined and refined by PHENIX11. Model building was performed with $\operatorname{Coot}^{12}$. The structures of the W191Y:L232E/H : WT Cc complex and the WT CCP : Y48K Cc complex were determined to $\sim 2.9 \AA$ and $\sim 1.9 \AA$ resolution, respectively, using molecular replacement with the parent W191Y:WT Cc and WT CCP:WT Cc structures as probes, respectively.

\section{Electron spin resonance spectroscopy}

CW-ESR: Compound I samples were prepared by combining $0.1-0.2 \mathrm{mM} \mathrm{CcP}$ and two molar equivalents of $\mathrm{H}_{2} \mathrm{O}_{2}$. The protein mixture was quickly loaded into an X-band ESR tube and flash frozen in liquid nitrogen within 30 seconds. Continuous-wave X-band spectra were acquired with a Bruker EleXSys II spectrometer at $9.39 \mathrm{GHz}$ and $12 \mathrm{~K}$ with $100 \mathrm{kHz}$ modulation frequency, 1 - 4 Gauss modulation amplitude, and $0.2-0.63 \mathrm{~mW}$ power. Power was varied to check for characteristic saturation effects of tyrosyl signals.

$\mathrm{D}_{2} \mathrm{O}$-treated samples were prepared by incubating $0.1-0.2 \mathrm{mM} \mathrm{CcP}$ in $100 \mathrm{mM} \mathrm{KPi}, \mathrm{pH} 6$ deuterium-based buffer overnight at $4{ }^{\circ} \mathrm{C}$. Compound I was generated upon addition of two 
molar equivalents of $\mathrm{H}_{2} \mathrm{O}_{2}$, quickly transferred to an X-band ESR tube, and flash frozen. A control sample in water-based buffer was prepared similarly to check for protein stability under identical conditions.

Rapid freeze quench experiments were carried out with a Bio-Logic SFM 300 machine that rapidly combines CcP samples with peroxide. As this method results in volume variations, instead of calculating a packing factor, an inert internal standard of Er:DTPA was added to the protein mixture. Er:DTPA was prepared by reacting a solution of $3 \mathrm{mM} \mathrm{Er}_{2}\left(\mathrm{SO}_{4}\right)_{3} \bullet 8 \mathrm{H}_{2} \mathrm{O}$ in $1 \mathrm{M}$ $\mathrm{HCl}$ with $8 \mathrm{mM}$ diethylenetriaminepentaacetic acid (DTPA; Sigma Chemical Company) in $0.1 \mathrm{M}$ $\mathrm{NaOH}$. The final $\mathrm{pH}$ was adjusted to 9. Samples containing $0.3 \mathrm{mM} \mathrm{CcP}, 1.5 \mathrm{mM}$ Er:DTPA, and $0.6 \mathrm{mM} \mathrm{Cc}$ in $100 \mathrm{mM} \mathrm{KPi}, \mathrm{pH} 6$ were mixed with $0.6 \mathrm{mM} \mathrm{H}_{2} \mathrm{O}_{2}$, and after a set time delay, the mixture was sprayed into liquid ethane-filled glass funnels that were coupled to X-band ESR tubes with heat shrink tubing. The resultant snow was immediately packed with an aluminum rod by hand into the bottom of an ESR tube. Spectra were collected with a Bruker EleXSys II spectrometer at $9.39 \mathrm{GHz}$ and $12 \mathrm{~K}$ with $100 \mathrm{kHz}$ modulation frequency, $4 \mathrm{~dB}$ modulation amplitude, and $0.6325 \mathrm{~mW}$ power. Data were processed by MatLab and EasySpin ${ }^{13}$.

The organic radical signal at $g=2$ was isolated and corrected by subtracting a linear baseline. Cumulative numerical integration (cumtrapz followed by integration trapz) was then implemented. The Er:DTPA signal at $g=11.8$ was similarly truncated, baseline corrected, and integrated with trapz. Tyr ${ }^{\bullet}$ signals were normalized to those of Er:DTPA.

Averaged RFQ signals were fit to biexponential equations assuming a competitive reaction model (Equation 6) and rate constants were solved for by Equation $7^{14,15}$. For parent Y191 data, rate constants $k_{\mathrm{r}}$ and $k_{\mathrm{obs}}$ were iteratively solved. However, for Y191:E232 data, owing to the noise of the data set, $k_{\text {obs }}$ was restrained such that the fit at $60 \mathrm{~s}$ was approximately equal to the averaged signal intensity between $15 \mathrm{~s}$ to $60 \mathrm{~s}$, and $k_{\mathrm{r}}$ was assumed to be $0 \mathrm{~s}^{-1}$ given no observed decrease of the signal intensities over the time course of the experiment. $A_{0}$ was 
measured by generating Y191 Cpd I RFQ samples without Cc using the same technique as described over similar time points (Table 1).

$$
\begin{gathered}
B(t)=\frac{A_{0} k_{f}}{\gamma_{2}-\gamma_{1}}\left(e^{-\gamma_{1} t}-e^{-\gamma_{2} t}\right) \\
\gamma_{1}+\gamma_{2}=k_{f}+k_{r}+k_{o b s} \\
\gamma_{1} \times \gamma_{2}=k_{r} \times k_{o b s}
\end{gathered}
$$

\section{ENDOR/ESEEM:}

Samples of $\sim 1$ to $1.5 \mathrm{mM}$ W191Y CCP and W191Y:L232E CcP were exchanged into $100 \mathrm{mM} \mathrm{KPi}$, $\mathrm{pH} 6,25 \%$ glycerol, $\mathrm{D}_{2} \mathrm{O}$-based buffer. After addition of peroxide to a final concentration of 3 $\mathrm{mM}$, each sample was rapidly transferred to a Q-band quartz capillary tube (Wilmad LabGlass; L: $100 \mathrm{~mm}$; OD: $1.6 \mathrm{~mm}$; ID: $1.1 \mathrm{~mm}$ ) and frozen in liquid nitrogen. Standards of L-tyrosine were prepared by dissolving $10 \mathrm{mM}$ L-tyrosine in $12.5 \mathrm{mM}$ sodium borate $\mathrm{D}_{2} \mathrm{O}$-based buffer, pD 10. Samples were frozen and irradiated for upwards of $15 \mathrm{~m}$ by a $36 \mathrm{~W}$ UV lamp at $77 \mathrm{~K}$.

ENDOR and ESEEM spectra were recorded on a BRUKER Q-Band ElexSys E580 FT pulse EPR spectrometer equipped with a pulsed ENDOR ElexSys E560-P accessory and a ColdEdge cryogen-free cooling system. The temperature for the pulse experiments was maintained at 60K. Pulse ENDOR measurements were performed according to the Mims sequence with a variation of the tau time to compensate for blind spots. Three-pulse ESEEM data were processed using exponential baseline subtraction before the Fourier transform.

\section{PCET thermodynamic and Brønsted analysis}

Bond dissociation free energies (BDFE) were calculated following the delineated relation ${ }^{16,17}$ using side chain acidities $\left(\Delta \mathrm{p} K_{\mathrm{a}}=\mathrm{p} K_{\mathrm{a}}\left(T y r^{\bullet}\right)-\mathrm{p} K_{\mathrm{a}}(\mathrm{HB}\right.$-acceptor $\left.)\right)$ and approximate CcP redox potentials relative to W191Y CCP ( $E^{\circ}$ in volts) with the appropriate coefficients to convert the calculated $\Delta \Delta G^{\circ \prime}=\Delta G^{\circ \prime}$ (variant) $-\Delta G^{\circ \prime}\left(\right.$ W191Y) into kcal mol ${ }^{-1}$ (Equation 4). Calculated BDFEs were compared to $-\mathrm{RT} \ln \left(k / k_{\mathrm{W} 191 \mathrm{\gamma}}\right)$, using rate constants from single turnover reactions. Scatterplots were fit with either a straight line to determine the slope $\alpha$ or were fit to Equation 8 to approximate $\Delta G^{\circ}{ }_{1}$ and $\lambda$. 


$$
\Delta \Delta G^{\ddagger \prime}=\Delta \Delta G^{\circ \prime 2}+2 \lambda \Delta \Delta G^{\circ \prime}+2 \Delta G^{\circ \prime}{ }_{1} \Delta \Delta G^{\circ \prime}
$$

To assess the dependency on side chain $\mathrm{p} K_{\mathrm{a}} \mathrm{s}, \Delta \Delta \mathrm{p} K_{\mathrm{a}}$ was fixed at 0 and BDFE values recalculated. The influence of the redox potential was evaluated in a similar manner. 


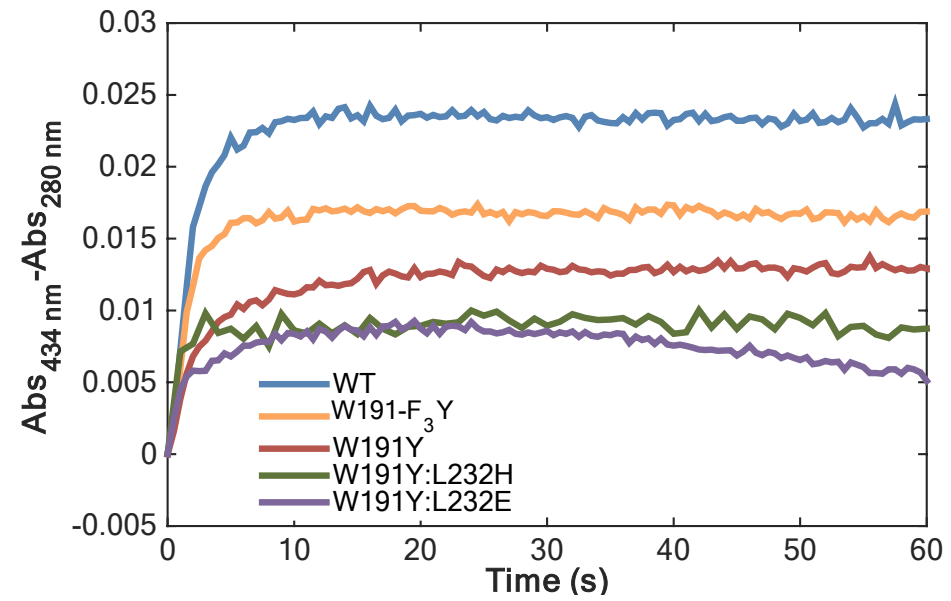

Supplemental Figure 1 - Progress curves for Cpd I formation. Reactions are shown for $1 \mu \mathrm{M} \mathrm{CcP}$ with $2 \mu \mathrm{M}$ peroxide in $100 \mathrm{mM} \mathrm{KP_{i }}$ buffer, $\mathrm{pH}$ 6. CcP variants have similar rates of $\mathrm{Cpd} \mathrm{I}$ formation but varying degrees of Cpd I stability, with the exception of W191Y:L2332E, which has somewhat reduced stability.

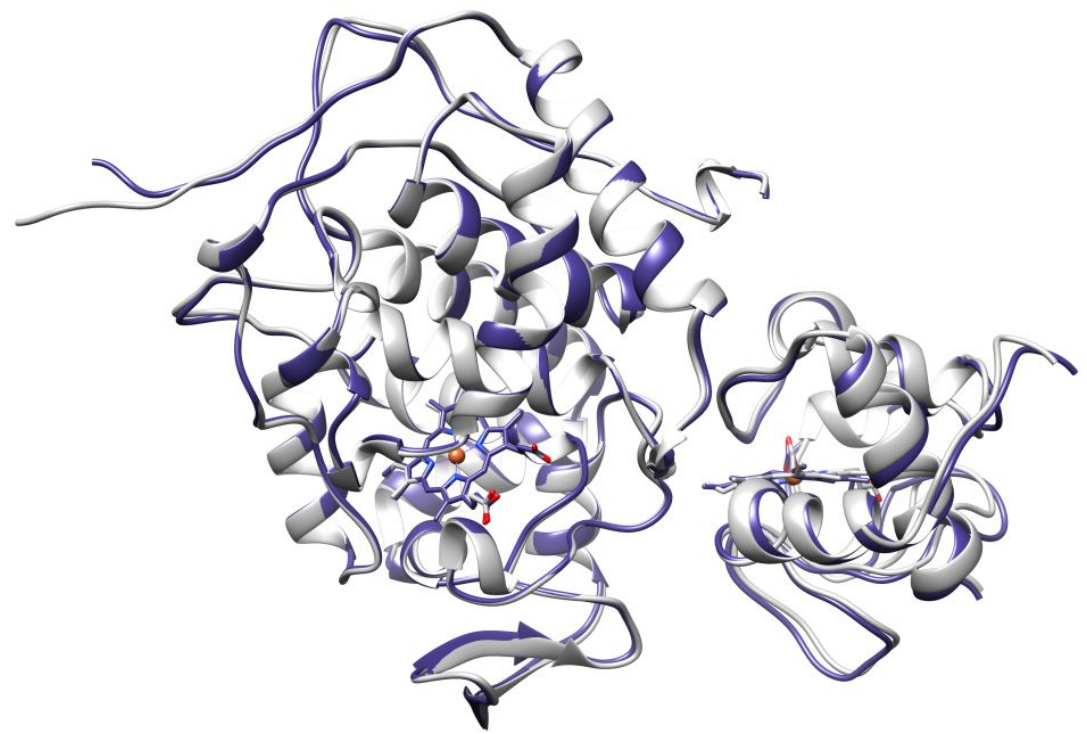

Supplemental Figure 2 - Crystal structure of WT CCP:CcY48K compared to that of WT CCP:WT Cc. Overlay of WT CcP:Y48K Cc (PDB 6P43; dark blue) and WT CcP:WT Cc (PDB 1U74; grey) shows no significant structural alterations between the two complexes. 


\begin{tabular}{|c|c|c|c|c|c|}
\hline \multirow[t]{2}{*}{ Variant } & \multirow[t]{2}{*}{$\mathrm{pH}$} & \multicolumn{2}{|l|}{ Single Turnover } & \multicolumn{2}{|c|}{ Multiple Turnover } \\
\hline & & $A$ & $k_{1}\left[\mathrm{~s}^{-1}\right]$ & $A$ & $k_{1}\left[\mathrm{~s}^{-1}\right]$ \\
\hline WT & 6 & $0.043 \pm 0.009$ & $0.48 \pm 0.09$ & $0.58 \pm 0.10$ & $0.43 \pm 0.06$ \\
\hline $\mathrm{WT}+\mathrm{Y} 48 \mathrm{~K} \mathrm{Cc}$ & 6 & $0.045 \pm 0.009$ & $0.45 \pm 0.08$ & - & - \\
\hline W191G & 6 & $0.0224 \pm 0.0014$ & $0.0221 \pm 0.0017$ & - & - \\
\hline W191Y & 6 & $0.021 \pm 0.007$ & $0.05 \pm 0.02$ & $0.66 \pm 0.11$ & $0.008 \pm 0.003$ \\
\hline$W 191 Y+Y 48 K C c$ & 6 & $0.023 \pm 0.009$ & $0.042 \pm 0.012$ & - & - \\
\hline W191Y:L232E & 6 & $0.044 \pm 0.004$ & $0.189 \pm 0.006$ & $0.101 \pm 0.018$ & $0.25 \pm 0.04$ \\
\hline W191Y:L232E & 7 & $0.023 \pm 0.002$ & $0.101 \pm 0.010$ & $0.387 \pm 0.017$ & $0.028 \pm 0.005$ \\
\hline W191Y:L232E & 8 & $0.0491 \pm 0.0016$ & $0.0128 \pm 0.008$ & $0.17 \pm 0.04$ & $0.0065 \pm 0.0007$ \\
\hline W191Y:L232E + Y48K Cc & 6 & $0.046 \pm 0.005$ & $0.156 \pm 0.005$ & - & - \\
\hline W191Y:L232H & 5 & - & - & $0.38 \pm 0.02$ & $0.0143 \pm 0.0010$ \\
\hline W191Y:L232H & 6 & $0.022 \pm 0.005$ & $0.114 \pm 0.016$ & $0.325 \pm 0.012$ & $0.014 \pm 0.004$ \\
\hline W191Y:L232H & 6.5 & - & - & $0.29 \pm 0.04$ & $0.037 \pm 0.007$ \\
\hline W191Y:L232H & 7 & $0.028 \pm 0.004$ & $0.079 \pm 0.014$ & $0.37 \pm 0.03$ & $0.037 \pm 0.005$ \\
\hline W191Y:L232H & 7.5 & - & - & $0.338 \pm 0.018$ & $0.027 \pm 0.003$ \\
\hline W191Y:L232H & 8 & $0.040 \pm 0.005$ & $0.053 \pm 0.008$ & $0.206 \pm 0.007$ & $0.0092 \pm 0.0012$ \\
\hline$W 191(3,5)-F_{2} Y$ & 6 & $0.0148 \pm 0.0019$ & $0.060 \pm 0.015$ & - & - \\
\hline $\mathrm{W} 191(2,3,5)-\mathrm{F}_{3} \mathrm{Y}$ & 6 & $0.022 \pm 0.006$ & $0.07 \pm 0.02$ & $0.554 \pm 0.017$ & $0.0149 \pm 0.005$ \\
\hline W191(2,3,5)-F $F_{3} Y: L 232 E$ & 6 & $0.046 \pm 0.003$ & $0.132 \pm 0.010$ & $0.22 \pm 0.05$ & $0.107 \pm 0.004$ \\
\hline W191 $(2,3,5)-F_{3} Y: L 232 E$ & 7 & - & - & $0.40 \pm 0.02$ & $0.024 \pm 0.005$ \\
\hline
\end{tabular}

Supplemental Table 1 - Single and multiple turnover rate constants from reactions run in 100 mM KPi buffer. Constants were obtained by fits to a first-order decay model. Scalar coefficients A should ideally be $\sim 0.04$ (single turnover; $2 \mu \mathrm{M} \mathrm{Cc}\left(\mathrm{Fe}^{2+}\right.$ )) and $\sim 0.58$ (multiple turnover; $30 \mu \mathrm{M}$ $\left.\mathrm{Cc}\left(\mathrm{Fe}^{2+}\right)\right)$, but owing to fluctuations in protein concentrations at early times and protein measurement variations, the first five seconds of the activity assays after mixing were omitted from some fits of the progress curves. 


\begin{tabular}{|c|c|c|c|}
\hline & W191YL232E:WT Cc & W191YL232H:WT Cc & WT:Y48K Cc \\
\hline & \multicolumn{3}{|c|}{ Data Collection } \\
\hline space group & $\mathrm{P} 2_{1}$ & $\mathrm{P} 2_{1}$ & P1 \\
\hline$a, b, c(\AA)$ & $45.80,112.07,88.33$ & $45.93,111.92,88.75$ & $45.21,50.89,86.43$ \\
\hline$\alpha, \beta, \gamma(\mathrm{deg})$ & $90,104.6,90$ & $90,105.6,90$ & $105.65,95.0,107.31$ \\
\hline no. of unique reflections & 18509 & 17827 & 43661 \\
\hline resolution ${ }^{\mathrm{a}}$ & $2.9 / 3.0-2.9$ & $2.9 / 3.0-2.9$ & $1.9 / 2.0-1.9$ \\
\hline completeness (\%) & $95.9 / 78.2$ & $83.7 / 45.9$ & $76.8 / 65.2$ \\
\hline $\mathrm{CC}_{1 / 2}$ & $0.99 / 0.56$ & $0.98 / 0.68$ & $0.99 / 0.57$ \\
\hline$\langle 1 / \sigma\rangle$ & $10.9 / 0.6$ & $6.7 / 0.6$ & $12.6 / 1.5$ \\
\hline \multirow[t]{2}{*}{$R_{\text {merge }}{ }^{b}$} & 0.175 & 0.164 & 0.076 \\
\hline & \multicolumn{3}{|c|}{ Refinement } \\
\hline $\mathrm{R}_{\text {work }}{ }^{\mathrm{c}}$ & $23.7 / 40.1$ & $21.2 / 34.6$ & $19.1 / 24.5$ \\
\hline$R_{\text {free }}^{c}$ & $27.3 / 44.4$ & $27.1 / 45.5$ & $22.8 / 29.4$ \\
\hline no. of atoms & 6522 & 6528 & 6439 \\
\hline no. of water molecules & 0 & 5 & 724 \\
\hline mean $B$ value $\left(\AA^{2}\right)$ & 89.5 & 68.1 & 25.5 \\
\hline B value (ligand) $\left(\AA^{2}\right)$ & 94.8 & 69.6 & 15.7 \\
\hline B value (waters) $\left(\AA^{2}\right)$ & - & 51.4 & 27.9 \\
\hline RMSD for bonds $(\AA ̊)$ & 0.004 & 0.007 & 0.005 \\
\hline RMSD for angles (deg) & 0.95 & 1.05 & 1.05 \\
\hline$\varphi / \psi$ stats $(\%)$ & & & \\
\hline $\begin{array}{l}\text { Ramachandran favored } \\
\text { (\%) }\end{array}$ & 94.2 & 93.3 & 96.8 \\
\hline $\begin{array}{l}\text { Ramachandran outliers } \\
\text { (\%) }\end{array}$ & 0.00 & 0.3 & 0.4 \\
\hline Rotamer outliers (\%) & 0.7 & 0.5 & 0.8 \\
\hline Protein Data Bank entry & 6P41 & $6 \mathrm{P} 42$ & $6 \mathrm{P} 43$ \\
\hline
\end{tabular}

Supplemental Table 2 - X-ray diffraction data collection and structure refinement statistics. ${ }^{a}$ Highest-resolution range for compiling statistics. ${ }^{\mathrm{b}} R_{\text {merge }}=\left(\sum_{\mathrm{i}} \sum_{\mathrm{j}}\left|l_{\mathrm{j}}-\left\langle l_{\mathrm{i}}\right\rangle\right|\right) /\left[\sum_{\mathrm{i}}\left(\sum_{\mathrm{j}} l_{\mathrm{j}}\right)\right]$, where $I_{\mathrm{j}}$ is the intensity of the jth observation of reflection $i,\left\langle I_{\mathrm{i}}\right\rangle$ is the average intensity of reflection $i$, and $N_{\mathrm{i}}$ is the redundancy of reflection $i .{ }^{c} R_{\text {work }}$ or $R_{\text {free }}=\left(\sum\left|F_{\text {obs }}-F_{\text {calc }}\right|\right) /\left(\sum\left|F_{\text {obs }}\right|\right)$. 


\begin{tabular}{|c|c|c|c|c|c|}
\hline Variant & $\Delta E^{\circ 1}(\mathrm{~V})$ & $\Delta \Delta \mathrm{p} K_{\mathrm{a}}$ & $\Delta \Delta G^{\circ}$ & $\begin{array}{l}\Delta \Delta G^{\circ 1} \\
\left(\Delta E^{\circ 1}=0\right)\end{array}$ & $\begin{array}{l}\Delta \Delta G^{\circ 1} \\
\left(\Delta \Delta \mathrm{p} K_{\mathrm{a}}=0\right)\end{array}$ \\
\hline W191Y CcP + WT Cc & 0 & 0 & 0 & 0 & 0 \\
\hline W191Y CcP + Y48K Cc & -0.10 & - & 2.31 & 0 & 2.31 \\
\hline W191Y:L232H CcP + WT Cc & 0.10 & -7.74 & 8.30 & 10.60 & -2.31 \\
\hline W191Y:L232E CcP + WT Cc & 0.20 & -5.99 & 3.59 & 8.21 & -4.61 \\
\hline W191Y:L232E CcP + Y48K Cc & 0.10 & -5.99 & 5.90 & 8.21 & -2.31 \\
\hline W191 $(3,5)-F_{3} Y$ CcP + WT Cc & -0.025 & -3.2 & 4.96 & 4.38 & 0.58 \\
\hline $\mathrm{W} 191(2,3,5)-\mathrm{F}_{3} \mathrm{Y}$ CcP $+\mathrm{WT} C \mathrm{C}$ & 0.039 & -3.9 & 4.44 & 5.34 & -0.90 \\
\hline$W 191(2,3,5)-F_{3} Y: L 232 E C c P+W T$ & 0.12 & -9.89 & & & \\
\hline Cc & & & 10.79 & 13.55 & -2.76 \\
\hline WT CcP + WT Cc & 0.30 & - & -6.92 & - & -6.92 \\
\hline WT CcP + Y48K Cc & 0.20 & - & -9.22 & - & -9.22 \\
\hline
\end{tabular}

Supplemental Table 3 - Estimated thermodynamic parameters affecting PCET of Tyr191*. $\Delta \Delta G^{\circ \prime}(\mathrm{kcal} / \mathrm{mol})$ was calculated as $\Delta \Delta G^{\circ \prime}=-23.06 \Delta E^{\circ \prime}-1.37 \Delta \Delta \mathrm{p} K_{\mathrm{a}}$. The values for $\Delta \Delta \mathrm{p} K_{\mathrm{a}}$ were determined from literature values of amino acids in aqueous solution ${ }^{6}$ relative to that of a hydronium ion, assuming that water accepts the proton in the case of W191Y; $\Delta E^{\circ \prime}(\mathrm{V})$ was approximated relative to that of W191Y CcP + WT Cc in $100 \mathrm{mM} \mathrm{KP}$ i buffer, pH 6; and -RT In $\left(k / k_{\mathrm{W} 191 \mathrm{Y}}\right)$ was calculated from single turnover rate constants in Supplemental Table 1.

Dependency on PCET was assessed by either fixing $\Delta \Delta \mathrm{p} K_{\mathrm{a}}$ or $\Delta E^{\circ \prime}$ to 0 . 


\section{References:}

(1) Payne, T. M.; Yee, E. F.; Dzikovski, B.; Crane, B. R. Constraints on the Radical Cation Center of Cytochrome c Peroxidase for Electron Transfer from Cytochrome C. Biochemistry 2016, 55 (34), 4807-4822.

(2) Pollock, W. B. R.; Rosell, F. I.; Twitchett, M. B.; Dumont, M. E.; Mauk, A. G. Bacterial Expression of a Mitochondrial Cytochrome c . Trimethylation of Lys72 in Yeast Iso-1Cytochrome c and the Alkaline Conformational Transition. Biochemistry 1998, 2960 (97), 6124-6131.

(3) DeWeerd, K.; Grigoryants, V.; Sun, Y.; Fetrow, J. S.; Scholes, C. P. EPR-Detected Folding Kinetics of Externally Located Cysteine-Directed Spin-Labeled Mutants of Iso-1Cytochrome C. Biochemistry 2001, 40 (51), 15846-15855.

(4) Vitello, L. B.; Huang, M.; Erman, J. E. PH-Dependent Spectral and Kinetic Properties of Cytochrome c Peroxidase: Comparison of Freshly Isolated and Stored Enzyme. Biochemistry 1990, 29 (18), 4283-4288.

(5) Gil, A. A.; Haigney, A.; Laptenok, S. P.; Brust, R.; Lukacs, A.; luliano, J. N.; Jeng, J.; Melief, E. H.; Zhao, R. K.; Yoon, E. Bin; Clark, I. P.; Towrie, M.; Greetham, G. M.; Ng, A.; Truglio, J. J.; French, J. B.; Meech, S. R.; Tonge, P. J. Mechanism of the AppA $_{B L U F}$ Photocycle Probed by Site-Specific Incorporation of Fluorotyrosine Residues: Effect of the Y21 PK $\mathrm{K}_{\mathrm{a}}$ on the Forward and Reverse Ground-State Reactions. J. Am. Chem. Soc. 2016, 138 (3), 926-935.

(6) Seyedsayamdost, M. R.; Reece, S. Y.; Nocera, D. G.; Stubbe, J. Mono-, Di-, Tri-, and TetraSubstituted Fluorotyrosines: New Probes for Enzymes That Use Tyrosyl Radicals in Catalysis. J. Am. Chem. Soc. 2006, 128 (5), 1569-1579.

(7) Minnihan, E. C.; Young, D. D.; Schultz, P. G.; Stubbe, J. Incorporation of Fluorotyrosines into Ribonucleotide Reductase Using an Evolved, Polyspecific Aminoacyl-TRNA Synthetase. J. Am. Chem. Soc. 2011, 133 (40), 15942-15945.

(8) Matthis, A. L.; Vitello, L. B.; Erman, J. E. Oxidation of Yeast Iso-1 Ferrocytochrome c by Yeast Cytochrome c Peroxidase Compounds I and II. Dependence upon Ionic Strength. Biochemistry 1995, 34 (31), 9991-9999.

(9) Miller, M. A. A Complete Mechanism for Steady-State Oxidation of Yeast Cytochrome c 
by Yeast Cytochrome c Peroxidase. Biochemistry 1996, 35 (49), 15791-15799.

(10) Miller, M. A.; Vitello, L.; Erman, J. E. Regulation of Interprotein Electron Transfer by Trp 191 of Cytochrome c Peroxidase. Biochemistry 1995, 34 (37), 12048-12058.

(11) Adams, P. D.; Afonine, P. V.; Bunkóczi, G.; Chen, V. B.; Davis, I. W.; Echols, N.; Headd, J. J.; Hung, L. W.; Kapral, G. J.; Grosse-Kunstleve, R. W.; McCoy, A. J.; Moriarty, N. W.; Oeffner, R.; Read, R. J.; Richardson, D. C.; Richardson, J. S.; Terwilliger, T. C.; Zwart, P. H. PHENIX: A Comprehensive Python-Based System for Macromolecular Structure Solution. Acta Crystallogr. Sect. D Biol. Crystallogr. 2010, 66 (2), 213-221.

(12) Emsley, P.; Lohkamp, B.; Scott, W. G.; Cowtan, K. Features and Development of Coot. Acta Crystallogr. Sect. D Biol. Crystallogr. 2010, 66 (4), 486-501.

(13) Stoll, S.; Schweiger, A. EasySpin, a Comprehensive Software Package for Spectral Simulation and Analysis in EPR. J. Magn. Reson. 2006, 178 (1), 42-55.

(14) Korobov, V.; Ochkov, V. Chemical Kinetics with Mathcad and Maple; Springer Vienna: Vienna, 2011.

(15) Bobrovnik, S. A. Determination the Rate Constants of Some Biexponential Reactions. J. Biochem. Biophys. Methods 2000, 42 (1-2), 49-63.

(16) Mayer, J. M. Proton-Coupled Electron Transfer: A Reaction Chemist's View. Annu. Rev. Phys. Chem. 2004, 55 (1), 363-390.

(17) Parker, V. D.; Handoo, K. L.; Roness, F.; Tilset, M. Electrode Potentials and the Thermodynamics of Isodesmic Reactions. J. Am. Chem. Soc. 1991, 113 (20), 7493-7498. 